\title{
An Approach towards Innovative Solution to B2B Competition
}

\author{
Souvik Paul ${ }^{1}$, Nabanita Das ${ }^{2}$, Soumyadeep Patra ${ }^{3}$ \\ I (BCA Department, The Heritage Academy, India) \\ ${ }^{2}(C S E \&$ IT Department, Bengal Institute of Technology, India) \\ ${ }^{3}$ (MBA Department, Sikkim Manipal University under Distance Education Mode, India)
}

\begin{abstract}
This dissertation researched what successful technology innovation project managers do. The primary objective of this research was to uncover insights on what the everyday look like for the project manager, and to build knowledge on the future of project management training. The interviews and observations based on the ethnographic tools and methods of contextual inquiry. The data collected has been analyzed with different ethnographic data analysis tools and methods, to extract insights both generic to every project manager, as well as differences between industries. This paper recommend a shift in the development of project managers from a strict tools and methods paradigm or a strict leadership paradigm, towards a development paradigm, where the six roles are developed simultaneously and in small steps, to make sure that no roles get too much attention. The complexity of the everyday of project managers indicates that even though prior research show little value of tools and methods, these may help structuring the complexity of projects.
\end{abstract}

Keywords: Innovations, B2B Markets, B2B Products, Ethnography, Contextual Design, Conceptual Framework.

\section{Introduction}

Business-to-business refers to a situation where one business makes a commercial transaction with another. This typically occurs when:

- A business is sourcing materials for their production process (e.g. a food manufacturer purchasing salt).

- A business needs the services of another for operational reasons (e.g. a food manufacturer employing an accountancy firm to audit their finances).

- A business re-sells goods and services produced by others (e.g. a retailer buying the end product from the food manufacturer).

B2B is often contrasted against business-to-consumer (B2C). In B2B commerce it is often the case that the parties to the relationship have comparable negotiating power, and even when they don't, each party typically involves professional staff and legal counsel in the negotiation of terms, whereas $\mathrm{B} 2 \mathrm{C}$ is shaped to a far greater degree by economic implications of information asymmetry.

\section{Innovations}

Invest in personalization as a part of your brand's online digital experience may seem risky for B2Bs, but your customers unconsciously want and expect you to provide custom-tailored products and services on your site, based on their previous history with your business and will reward you with more sales or conversions when set up properly. An underlying benefit of presenting your online customers with dynamic content is that they will stay on your website longer, visit more often, and engage more with your business. Whether they spend their time reading your blog, exploring the products and services you have to offer, downloading an interest form or whitepaper, or, most importantly, making a purchase, keeping users engaged with your website provides myriads of advantages.

\section{B2B Markets}

In most households, even the most complex of decisions is confined to the small family unit while items such as clothes, food and cigarettes usually involve just one person. The decision making unit (DMU) in business-to-business markets is highly complex or at least it has the potential to be so. Ordering products of low value and low risk (such as the ubiquitous paper clip) may well be the responsibility of the office junior. However, the purchase of a new plant that is vital to a business may involve a large team who makes their decision over a protracted period. The DMU at any one time is often ephemeral - specialists enter and leave to make their different contributions and, of course, over time people leave the company or change jobs far more frequently than they change family unit. This complexity and dynamism has implications for business-tobusiness markets. The target audiences for B2B communications are amorphous, made up of groups of constantly changing individuals with different interests and motivations. Buyers seek a good financial deal. 
Production managers want high throughput. Health and safety executives want low risk. And those are just their simple, functional needs. Each person who is party to the DMU will also bring their psychological and cultural baggage to the decision and this can create interesting variations to the selection of products and suppliers.

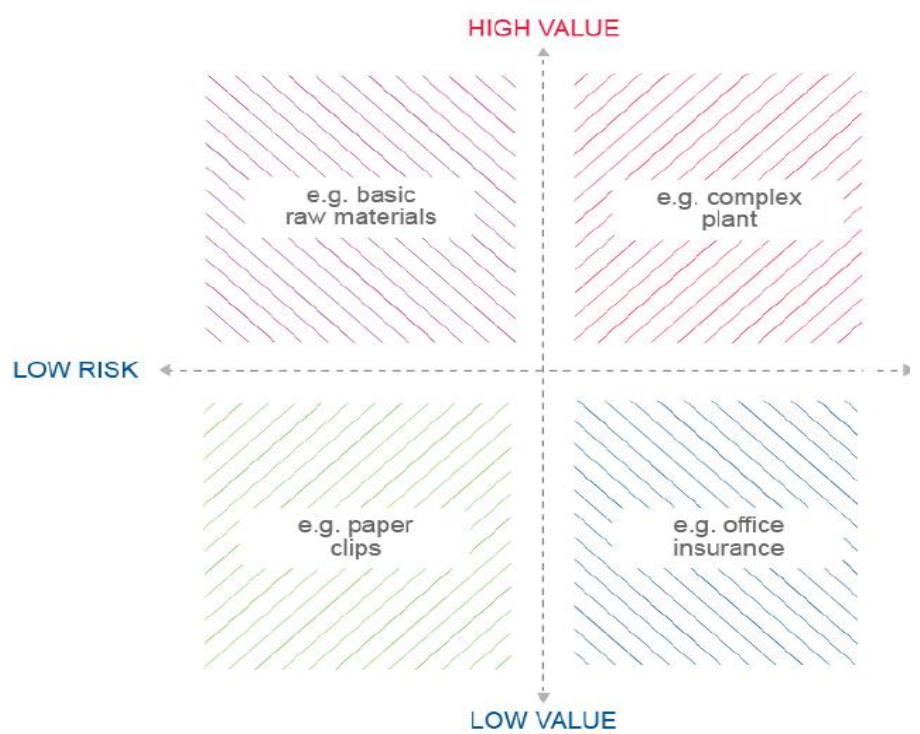

Figure 1: The Risk-Value Purchasing Decision Matrix in Business-to-business Marketing

Figure 1 above divides business-to-business purchases into four categories according to their financial value and the level of business risk associated with the purchase. Each of these categories gives rise to different purchasing behavior and different complexities.

- Low-risk, low-value purchases are the least distinct from consumer purchases. They often involve just one, frequently junior person. There is little financial or business risk involved on getting the decision wrong, meaning that relatively little thought goes into the decision.

- Low-risk, high-value items such as raw materials typically involve a mixture of technical and purchasing personnel, and often very senior people such as board members. This complexity is necessary to ensure that price is minimized without impacting upon quality. Purchasing personnel would usually be the key decision makers on a transaction-by-transaction basis, under the general guidance of more technical employees, who would review suppliers periodically.

- Low-value, high-risk items such as office insurance would similarly involve a mixture of specialists and purchasers. As the 'risk' is in the product rather than the price, and as each transaction is likely to be unique, an expert (in this case perhaps an in-house legal expert) would tend to be the key decision maker every time a purchase takes place.

- High-value, high-risk purchases are the most distinct from consumer purchases, with a large number of senior decision makers evaluating a large range of purchase criteria. In the case of plant equipment, we might expect a CFO, R\&D Director, Production Director, Purchasing Director, Head of Legal Department, $\mathrm{CEO}$ and a number of upper-management department heads to be involved.

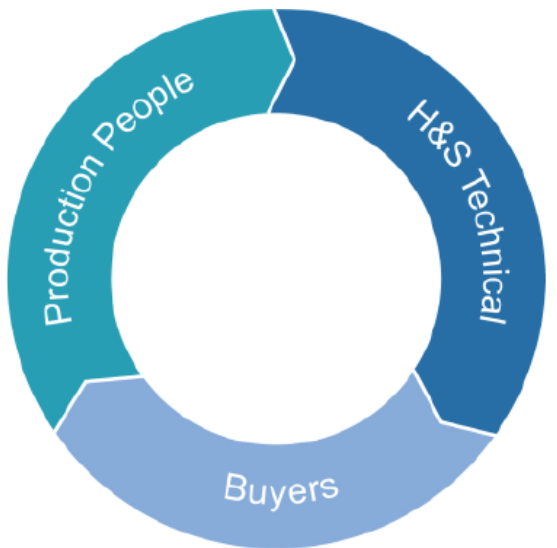

Figure 2: A Typical Decision Making Unit in A B2B Environment 


\section{B2B Products}

Just as the decision making unit is often complex in business-to-business markets, so too are B2B products themselves. Where the purchase of a consumer product requires little expertise (perhaps nothing more than a whim), the purchase of an industrial product frequently requires a qualified expert. Where consumer products are largely standardized, industrial products are often bespoke and require high levels of fine tuning. Even relatively complex consumer products tend to be chosen on fairly simple criteria. A car might be chosen because it goes fast and looks nice, and a stereo might be purchased on the grounds that it is tremendously loud. Even simpler industrial products, on the other hand, frequently have to be integrated into wider systems and as a result have very specific requirements and need intimate, expert examination and modification. It is difficult to imagine a turbine manufacturer or commercial website design buyer having a look at three or four products and then choosing one simply because it looks nice. The choice of turbine will involve a whole host of technical, productivity and safety issues, whilst the choice of website might be based on its integration into a wider B2B marketing campaign, its interactivity with users and the degree to which it draws potential clients via search engines.

Buyers of consumer products are generally not interested in the technical details of what they are buying. The vast majority of car buyers are far more interested in what speed the car will reach than in how it will reach that speed. Similarly, the buyer of a chocolate bar is likely to be far more interested in the fact that the item stops them feeling hungry and tastes nice than in the technology and ingredients that make it so. As a result, consumer products are frequently marketed in ways that are superficial or even vacuous.

\section{Ethnography}

Ethnography is the systematic study of people and culture, a study where the researcher "immerse" into the setting that is observed, essentially a form of scientific fieldwork in which an observer makes first hand observations and taking notes about a participant or participants (Nicholas, 2008, Easterly-Smith et al., 2012). It is originally based on anthropology (Simmons, 2007), the science of mankind in general. A distinction is often made between anthropology, studying culture, social structures, etc. Whereas anthropological methods typically involves the observer to immerse into a setting for years, e.g. living with distant tribes in the jungle, to understand their culture, social structures and life in general, ethnographic methods aims to reveal the necessary insights much faster, and investigation may be limited to only a few cases (O'Reilly, 2005).Our objective is to create possible new insights, the ethnographic approach is considered a useful approach, to open up experiences during research where other research methods fail to cover. Moreover it helps in vast varied understanding about the depth of knowledge.

\section{Contextual Design}

Contextual Design (CD) is a structured user-centered design process based on ethnography (Holtzblatt, 2014). The strength of CD is that it provides a well structured process and well defined methods to collect data about people in the field, interpret and consolidate the data in a structured way. Originally the method was designed to be used in human-computer interaction studies (Curtis et al., 1999), and software development (Rockwell, 1999). However it has also been use in process reengineering, device design etc (Holtzblatt, 2014). The key principle is that people are experts in their own lives, but are unable to articulate their knowledge explicitly. Therefore it is important to observe and interview people where they live and where they do their work. The process is based on two main phases; collection and concept development, each with 4 subprocesses (Holzblatt, 2014):
1. Collection
a. Contextual Inquiry - field work
b. Interpretation session
c. Work models and affinity diagramming - data consolidation
d. Visioning - redesign peoples work with new technology ideas

\section{Concept Development}

a. Story boarding - work out the details of particular tasks and roles

b. User Environment Design - design system to support the new work

c. Paper Mock-up Interviews - low resolution prototypes are tested with the customer

d. Interaction and Visual Design - design and test the final look and user experience. 


\section{Conceptual Framework}

Group of concepts that are broadly defined and systematically organized to provide a focus, a rationale, and a tool for the integration and interpretation of information. Usually expressed abstractly through word models, a conceptual framework is the conceptual basis for many theories, such as communication theory and general systems theory. Summing up the literature a framework emerges, consisting of:

- Six roles of an innovation project manager

- A framework for project success

- 13 critical success factors for projects

- A three determinant category framework for team success

- The external influence on project success; culture; processes and the sponsors.

\section{Project Success}

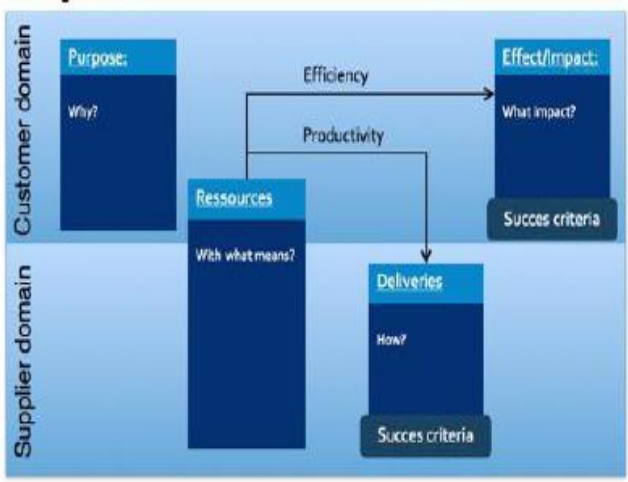

13 critical success factors of projects

\begin{tabular}{|c|c|c|c|c|}
\hline & $\begin{array}{l}\text { Andersen } \\
\text { et. al } 2006\end{array}$ & $\begin{array}{l}\text { Mir \& } \\
\text { Pinnington } \\
2014\end{array}$ & $\begin{array}{l}\text { Mishra, } \\
\text { Dangayach } \\
\text { and Mittal } \\
2011\end{array}$ & $\begin{array}{l}\text { Ong. ot. al. } \\
2009\end{array}$ \\
\hline Strong commitmont & $x$ & & & $\mathrm{x}$ \\
\hline Rich communication & $x$ & & & $\mathrm{x}$ \\
\hline Early stakeholder influence & $x$ & & & $x$ \\
\hline Stakeholder endorsement of plans & $x$ & & & $x$ \\
\hline Strong Project KPI's & & $x$ & & \\
\hline The project team & & $x$ & 2 & \\
\hline $\begin{array}{l}\text { Project leadership/the project } \\
\text { manager }\end{array}$ & & $x$ & 1 & \\
\hline Project lifecycle management & & $x$ & & \\
\hline Project tools and techniques & & & 3 & \\
\hline Project organization & & & 4 & \\
\hline External factors & & & 5 & \\
\hline Create an appropriate culture for PM & & & & $\mathrm{x}$ \\
\hline Managing the dynamics of change & & & & $\mathrm{x}$ \\
\hline
\end{tabular}

\section{Team Success Determinants}
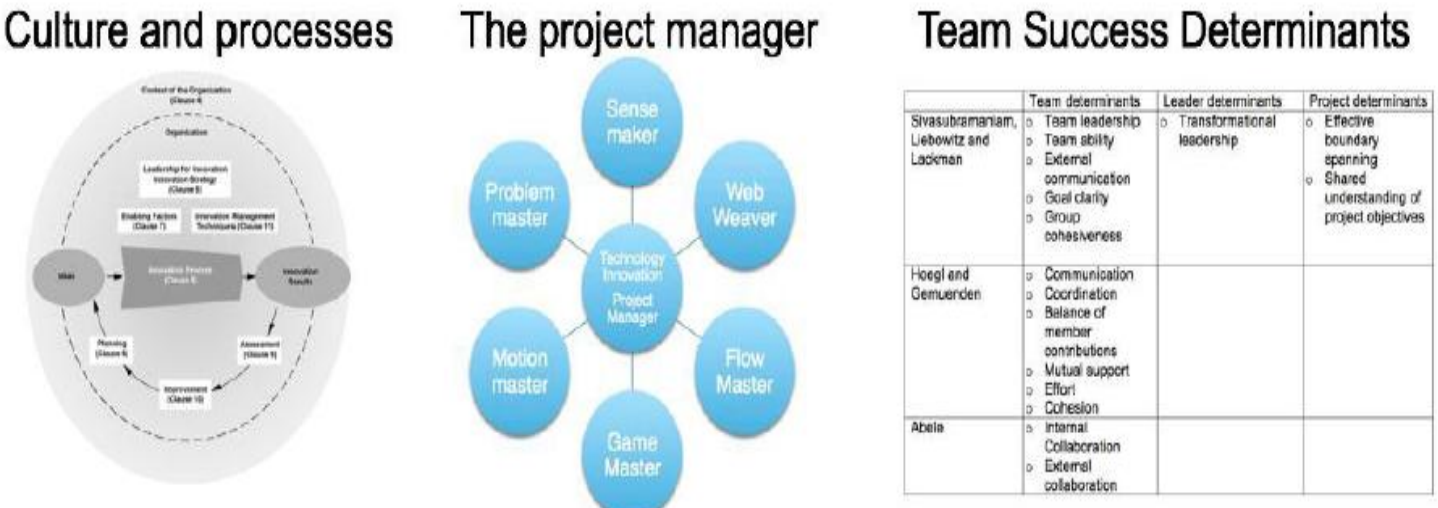

Figure 3: Theoretical framework of the research

\section{Conclusions}

The use of corresponding interpretation methods creates a skeleton and process of the ethnographic observations and interviews in this research, it has however to be tailored against the objectives. There are also risks embedded in the fact that the observed are only observed in a very limited fraction of their time, and thus only limited fragments of their work may be discovered. Therefore the interviews has to have some exploratory approach, e.g. asking the project manager to open his electronic calendar and tell about the work of every single day the last week, and e.g. to ask him to show around in the project room, and tell about what and when they use every single artifact. As the research is conducted as both daylong observations, and shorter interview sessions, it is important to bear in mind, that in interview settings, people may think they help saving time by pointing out something they think is important. This behavior may reduce the quality of the data that is collected. Therefore the immediate interpretation with the interviewee is crucial to quality of the data, as well as the possibility to cross check findings across several interviews.

\section{Acknowledgements}

We are thankful to The Heritage Academy, Bengal Institute of Technology and Sikkim Manipal University to give us the opportunity to work on the interesting topic. 


\section{Include these Details:}

\section{References}

[1] DEBBIE MILLMAN , (2013), Brand Bible: The Complete Guide to Building, Designing and Sustaining Brands

[2] MELISSA ARONCZYK, (2013), Branding the Nation: The Global Business of National Identit, New York

[3] CARLOS MARTINEZ ONAINDIA, (2013), Designing B2B Brands: Lessons from Deloitte and 195,000 Brand Managers, NJ

[4] Aaker, David. Brand Portfolio Strategy. Free Press, 2004.

[5] "Nielsen Monitor-Plus Launches Quick*Views." Nielsen Media Research. Press Release, 21 August 2003.

[6] Simms, Jane. "Stretching Core Value." Marketing. 19 October 2000

\section{Journal Papers:}

[1] "Top 100 Global Brands Scoreboard." Business Week Online. Available fromhttp://bwnt.businessweek.com/brand/2005/. Retrieved on 10 January 2006.

[2] U.S. Department of Homeland Security. U.S. Customs Bureau. "Yearly Comparisons: Seizure Statistics of Intellectual Property

Books: Rights." Available from www.cbp.gov/xp/cgov/import/commercial_enforcement/ipr/seizure/seizure_stats.xml

[1] E-Commerce : Business, Technology, Society by Kenneth C. Laudon and Carol G.Traver, Prentice Hall, 4th Edition, 2008.

[2] Electronic Commerce 2010-A Managerial Perspective by Efraim Turban, David King, Jae Lee, Ting Liang, Deborrah Turban, 6th Edn., Pearson Education.

[3] e-Commerce: Strategy, Technologies And Applications By David Whiteley, McGraw Hill, 2000.

[4] Enterprise Resource Planning by Mary Sumner, Pearson Education, 2008. 